\title{
EDITORIAL
}

\section{Paediatric HERMES: update of the European Training Syllabus for Paediatric Respiratory Medicine}

\author{
M. Gappa, J. Paton, E. Baraldi, A. Bush, K-H. Carlsen, J.C. de Jongste, E. Eber, B. Fauroux, S. McKenzie, \\ J-L. Noël, P. Palange, P. Pohunek, K. Priftis, T. Séverin, J.H. Wildhaber, Z. Zivkovic and M. Zach
}

B y providing free access for European medical specialists to the European job market via two relevant directives (issued in 1975 and 2005), the European Union (EU) has effected an automatic recognition of the diplomas and certificates of qualification in medicine in all member countries. This is only acceptable on the basis of harmonised training standards across the entire EU. Thus, it is mandatory to work towards such harmonised standards in all medical specialties.

As a result of the first directive and more than 10 years ago, the Long Range Planning Committee of the Paediatric Assembly of the European Respiratory Society (ERS), led by M. Zach, developed the first European syllabus for Training in Paediatric Respiratory Medicine as a tertiary care subspecialty. This pioneering syllabus not only served as a model for other tertiary care subspecialties in paediatrics but also helped establish and strengthen paediatric respiratory medicine (PRM) as a subspecialty within Europe. With the syllabus as a guide, the ERS Paediatric Assembly and the ERS School have continuously promoted state-of-the-art training in PRM.

In contrast to adult respiratory medicine, which has long been established as a specialty in most European countries, PRM is still developing as a subspecialty in Europe [1]. Widely different approaches to training are still the reality in EU states. Formal training in a recognised training centre is the norm in countries such as the UK, the Netherlands, Germany, Austria and Switzerland; in other countries there is no formal recognition of PRM, and junior doctors have to train abroad or in adult respiratory depts. Training in particular areas sometimes occurs in other subspecialties, such as allergology or neonatology, or within general paediatrics. In response to the heterogeneity of training and specialty recognition, the 2002 PRM syllabus sought to harmonise the different national training concepts in existence throughout Europe [2].

For author affiliation details, please see the Acknowledgements.

STATEMENT OF INTEREST: A statement of interest for K-H. Carlsen and J.H. Wildhaber can be found at www.erj.ersjournals.com/misc/statements.shtml

CORRESPONDENCE: M. Gappa, Children's Hospital, Marien-Hospital Wesel, Pastor-Janssen-Str. 838, D-46483, Wesel, Germany. Fax: 49 2811041178. E-mail: monika.gappa@marien-hospitalwesel.de Alternatively, contact J-L. Noël at Julie-lyn.noel@ersnet.org

\section{THE NEED FOR AN UPDATE}

An online survey of members of the ERS Paediatric Assembly performed in 2006 revealed that many of the respondents found the first syllabus useful, both for personal practice as well as for establishing training programmes at a national level. However, the overwhelming majority also highlighted the need for an update of the syllabus to reflect changes in practice and to take into account political changes in the field of medicine in their countries.

Using the example of the Adult HERMES (Harmonised Education in Respiratory Medicine for European Specialists) Task Force, an ERS Paediatric HERMES Task Force began the task of updating the syllabus. The 2002 PRM syllabus already offered a clearly defined model and its modular structure provided a solid basis for the work of the Task Force [3]. The Task Force commenced work in September 2007 and aimed to develop recommendations for training European specialists in PRM which were both realistic (i.e. defining minimum standards) and aspirational (i.e. reflecting best practice).

\section{A NEW EDUCATIONAL MILESTONE}

The final updated European Paediatric Respiratory Medicine Syllabus has now been published [4]. This syllabus was produced using a three-round Delphi consensus process in close collaboration with a cohort of 28 experts and 29 trainees in PRM. The cohort of experts comprised 15 Task Force members and 13 national respondents representing 20 countries. Respondents had been nominated by their respective national societies.

The basis for entering specialist training in PRM is defined as at least a 3-year period of training in general paediatrics as recommended by the European Academy of Paediatrics (EAP). The content of the tertiary care level of training includes: 21 mandatory modules (respiratory symptoms and signs, pulmonary function testing, airway endoscopy, imaging, acute and chronic lung infection, tuberculosis, cystic fibrosis, bronchial asthma, allergic disorders, congenital malformations, bronchopulmonary dysplasia, rare diseases, sleep medicine, rehabilitation, inhalation therapy, technology-dependent children, epidemiology and environmental health, management and leadership, teaching, communication, and research) and three optional modules (rigid and interventional endoscopy, post lung transplant management, and additional diagnostic tests), with the level of competence to be achieved. The syllabus will be submitted for approval by the EAP and it is anticipated that no important changes will be needed. 


\section{CHALLENGES: ACCEPTABILITY AND APPLICABILITY}

How this new syllabus is accepted and implemented will differ from country to country. Flexibility has to be important, otherwise parts of Europe may be unable to offer training in PRM. Its applicability will also vary depending on local facilities e.g. training centre size and available resources. The Task Force is conscious of the basic EU principle of subsidiarity, which does not give any legal standing to the initiative and therefore the syllabus will remain a recommendation. The Task Force is also aware of the existence of local or national resistance to the official recognition of PRM. It is hoped that publication of this new syllabus will aid the evolution of PRM as a recognised subspecialty in an increasing number of countries. Clearly, the aim is that all PRM training centres and trainees should study the syllabus to ensure that the mandatory modules are being achieved during the training period.

\section{LOOKING AHEAD}

The updated syllabus marks the first step in an ambitious programme of the Paediatric HERMES initiative. The development of a PRM curriculum is currently being actively tackled at high speed. The curriculum will describe in detail recommended methods for training and assessment of training in PRM. This should be followed by a centre visitation programme for accreditation of training centres and the development of training networks throughout Europe. The development of comprehensive educational materials such as e-learning resources, and courses and seminars to facilitate training, will be a challenge for the ERS School in the coming years.

The groundwork for a voluntary knowledge-based European examination in PRM has also begun. The goal is to hold the inaugural examination at the 2010 ERS Annual Congress in Barcelona. As PRM is a small subspecialty, developing a European exam will provide a rigorous assessment of a trainee knowledge that will not be easily duplicated within individual states.

\section{A FUTURE VISION}

Respiratory diseases are among the leading causes of morbidity and mortality in children. With this first syllabus milestone, the Paediatric HERMES Project looks forward to the development of modern standardised European training for the PRM specialty. Standardisation of training across Europe, including quality control for all aspects of training combined with robust assessments of competence, will facilitate the free movement of trainees with appropriate language skills between centres and nations in Europe.

As PRM continues to develop, the new syllabus will need to be revised regularly. The Task Force also realises that there is a demand for a definition of training requirements for general paediatricians with a special interest in PRM working in secondary or primary care settings, and will act accordingly.

It is hoped that by updating the existing syllabus and responding to the needs of the paediatric respiratory community, the new syllabus will further strengthen paediatric respiratory medicine in Europe. We look forward to the day when all children with respiratory illnesses benefit from the very best of the specialist knowledge and expertise available in Europe.

\section{ACKNOWLEDGEMENTS}

Author affiliation details are as follows. M. Gappa: Klinik für Kinder- und Jugendmedizin, Marien-Hospital Wesel GmbH, Wesel, Germany. J. Paton: University of Glasgow, Division of Developmental Medicine, Yorkhill NHS Trust, Glasgow, UK. E. Baraldi: Paediatric Pneumology, University of Padova, Padova, Italy. A. Bush: Dept of Paediatric Respiratory Medicine, Royal Brompton Hospital, London, UK. K-H. Carlsen: Voksentoppen, Dept of Paediatrics, Rikshospitalet Radiumhospitalet, Medical Center, Oslo, Norway. J.C. de Jongste: Erasmus University Medical Center, Sophia Children's Hospital, Rotterdam, the Netherlands. E. Eber: Univ.-Klinik fuer Kinder- und Jungendheilkunde, Graz, Austria. B. Fauroux: Pneumologie Pédiatrique, Centre de la Mucoviscidose, Hôpital Armand Trousseau, Paris, France. S. McKenzie: Royal London Hospital, Paediatric Respiratory Unit, London, UK. J-L. Noël and T. Séverin: ERS Headquarters, Lausanne, Switzerland. P. Palange: Policlinico Umberto I University of Rome, Rome, Italy. P. Pohunek: Dept of Paediatric Respiratory Diseases, University Hospital Motol, Prague, Czech Republic. K. Priftis: Allergy Pulmonology Dept, Penteli Children's Hospital, Athens, Greece. J.H. Wildhaber: Dept of Paediatrics, Hospital Fribourgeois, Fribourg, Switzerland. Z. Zivkovic: Center for Pediatric Pulmonology, Medical Center Dr Dragisa Misovic, Belgrade, Republic of Serbia. M. Zach: Paediatric Dept, University Kinderklinik, Graz, Austria.

\section{REFERENCES}

1 Godfrey S, Carlsen KH, Landau L. Development of pediatric pulmonology in the United Kingdom, Europe, and Australasia. Pediatr Res 2004; 55: 521-527.

2 Zach MS, Long Range Planning Committee, Paediatric Assembly of the European Respiratory Society, Committee on Paediatric Respiratory Training in Europe, European Board of Paediatrics. Paediatric respiratory training in Europe: syllabus and centres. Eur Respir J 2002; 20: 1587-1593.

3 Loddenkemper R, Séverin T, Eiselé JL, et al. HERMES: a European core syllabus in respiratory medicine. Breathe 2006; 3: 59-70.

4 Gappa M, Noël J-L, Séverin T, et al. Paediatric HERMES: a European Syllabus in Paediatric Respiratory Medicine. Breathe 2009; (In press). 